\title{
The Reliability of Eyewitness Testimony
}

\author{
Fangting Liu, ${ }^{1, *}$ \\ ${ }^{1}$ Durham University, Department of Psychology, Durham, UK \\ "Corresponding author. Email: 1582255345@qq.com
}

\begin{abstract}
Eyewitness testimony has always played an important role in the courtroom, helping judges to make decisions, so it is widely considered to be reliable. However, there is growing research evidence that the accuracy of the eyewitness testimony is influenced by many factors, including personal factors such as age and gender, as well as extraneous factors such as the way questions are asked, mental state of eyewitness, and environmental factors. So testimony is not entirely reliable, and erroneous evidence can adversely affect a judge's decision in court, it can even lead to the conviction of innocent people. Therefore, although eyewitness testimony is valuable, when using it, it is important to consider whether numerous factors may affect its accuracy. The purpose of this essay is to analyze two important influencing factors, questioning style and the mental state of the eyewitness, and also discuss how they affect memory reliability. It is shown that both the suggestive information and the type of questions asked may expose the witness to misleading information. In addition, different emotional tones and under conditions of severe emotional arousal also have different effects on testimony.
\end{abstract}

Keywords: Eyewitness testimony, memory, reliability.

\section{INTRODUCTION}

Eyewitness testimony is one of the most common forms of evidence in litigation trials, and the evidence they provide determines the outcome of the trial, so its reliability and veracity have always been of concern to experts in the field. According to researchers investigating DNA evidence-based exonerations, the most significant cause of wrongful convictions in US courts is inaccurate eyewitness memory, as the original memory can be altered by people's subsequent knowledge or beliefs [1]. This phenomenon of memory is a false memory, where people's reports of past events deviate from the truth, but the person does not notice. Wrong eyewitness testimony can lead to people being unlawfully imprisoned for not giving the judge the right guidance [2]. So psychologists have conducted many studies on eyewitness testimony, and proved that it can be influenced by many factors. Such as personal factors, if the eyewitness is very young, or has a mental illness, mental deficiency, etc., then the testimony may not play much of a role [3]. Also, many external factors can affect the accuracy of testimony, the questioning style and the emotion of eyewitness being two important influences. Therefore, this essay will focus on how these two factors influence eyewitness testimony, it can contribute to a better understanding of the factors that influence people's memories, and help the judge to make trade-offs with the testimony.

\section{QUESTIONING STYLE}

First of all, a number of studies have shown that inappropriate methods of questioning, including suggestive questions, tone of voice and expression during questioning and so on, can expose witnesses to misleading information and affect the reliability of their testimony [4]. Firstly, suggestive information in the questions can affect the eyewitness's memory. Research interests in the effect of eyewitness under post-event conditions are based on the research by Elizabeth Loftus [5]. A study was conducted by Loftus and Palmer on people's memories in 1974. During the experiment, participants were divided into two groups after watching a video of a car speeding and causing a rear-end collision, with one group being asked questions that contained false assumptions, such as "how fast was the car going past the barn when it was moving", and the other group being asked only "how fast was the car going when it was moving ". Based on the participants' responses, the results showed that participants in the first group were more likely to report that they had seen the barn in the video, when in fact it did not appear in the video at all [5]. This shows that false memories are sometimes derived from false cues, which can implant memories into people's 
brains, so that eyewitnesses' memories can be misled by questions or hints about the event that are asked by others afterwards. Loftus argues that augmenting, degrading or being integrated into the memory of the event with post hoc information can alter the content of the original memory, which is known as the misinformation effect, it is a manifestation of false memory [6]. And the more people are exposed to misinformation, the more likely they are to attribute that misinformation to the original event. This can be explained by the theory of familiarity, as the presence of frequent misinformation creates a strong memory in witnesses, making them believe that the information was experienced visually in a real way and therefore highly recognize it [7]. Since then, many studies have been conducted using the misinformation effect, and have confirmed that people attribute misinformation generated in narratives and questions following an event to an event that was witnessed. In these studies, there were two other findings regarding the misinformation effect: firstly, participants attributed misinformation to the original event even though they were explicitly informed that they might receive it [8]. Also, participants tended to express very confident judgments about the source of these misinformations, further proof that this is not an error of conjecture, but with firm conviction [9]. All of this evidence suggests that the wrongly implied information in the questioning would have led the witnesses to believe strongly that these were their real experiences, and therefore lead to inaccurate testimony.
Secondly, the type of questions asked can also have an impact on the reliability of the testimony, including open-ended questions, i.e. questions that do not contain any guidance. There are no restrictions on what or how the answer can be given; and specific questions, i.e. questions that lead the witness to give an answer, such as "yes" or "no" [4]. Peterson and Bell have done research on this. In the experiment they designed, participants were patients who had been injured a week before, and they were asked to answer questions related to their injuries. The study found that when the questions were open-ended, such as "How did you get hurt?" , "Who were you with when you were injured?" etc., the patients' answers were very accurate, but when the questions were specific, such as "Did it hurt?" and "Did you cry?", the patients' answers were biased. Table 1 shows that whether in the initial interview or the follow-up interview, participants were able to provide the most details of information in free recall. And the results also showed that free recall was very accurate. In the initial interview, only $9 \%$ of all errors made by participants being in free recall, compared to $41 \%$ of errors caused by yes/no questions. It is because open-ended questions were more conducive for people to express, so the more accurate the memory is recalled [10]. Therefore, if investigators want to make the eyewitness testimony more detailed and accurate, they can ask more open-ended questions. However, open-ended questions may not provide the clues to an eyewitness' recollection as specific questions, so flexibility in the type of questioning applied is required to achieve the best possible standard.

Table 1. Average percentage of free recall, Wh-questions and yes/no questions eliciting information

The Mean Percentage of Children's Central, Peripheral-Inside, and Peripheral-Outside Information That Is Elicited by Free Recall, WH- Questions, AND Yes/No QUESTIONS DURING BOTH INTERVIEWS

\begin{tabular}{|c|c|c|c|c|c|c|c|}
\hline \multirow{2}{*}{$\begin{array}{c}\text { TYPE OF } \\
\text { QUESTIONS }\end{array}$} & \multicolumn{6}{|c|}{ ChILdREN's AGE IN YeARS } & \multirow[b]{2}{*}{ MEAN } \\
\hline & 2 & 3 & 4 & 5 & 9 & 13 & \\
\hline \multicolumn{8}{|l|}{ Initial interview: } \\
\hline \multicolumn{8}{|l|}{ Central: } \\
\hline Free ......................... & $45.2(26.7)$ & $40.7(17.2)$ & $38.9(16.4)$ & $56.9(11.8)$ & $62.0(18.9)$ & $80.3(19.6)$ & $54.1(23.4)$ \\
\hline Wh- .......................... & $41.5(18.6)$ & $45.4(18.7)$ & $52.0(15.8)$ & $36.4(16.1)$ & $\begin{aligned} 33.7(17.7) \\
4.1(5.7)\end{aligned}$ & $19.0(19.7)$ & $\begin{aligned} 38.0(20.2) \\
7.8(10.2)\end{aligned}$ \\
\hline \multicolumn{4}{|l|}{ P-In: } & & & $.5(2.1)$ & $7.8(10.2)$ \\
\hline 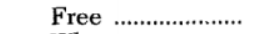 & $14.9(28.1)$ & $8.5(15.9)$ & $20.9(20.2)$ & $45.9(18.0)$ & $35.1(26.2)$ & $49.4(22.5)$ & $29.1(26.6)$ \\
\hline 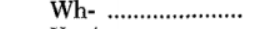 & $58.5(45.1)$ & $91.5(15.9)$ & $79.1(20.2)$ & $54.1(18.0)$ & $64.9(26.2)$ & $50.6(22.5)$ & $66.4(29.6)$ \\
\hline 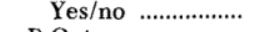 & $\begin{array}{ll}.0 & (.0)\end{array}$ & $.0 \quad(.0)$ & $.0 \quad(.0)$ & $.0 \quad(.0)$ & $.0 \quad(.0)$ & $.0 \quad(.0)$ & $.0 \quad(.0)$ \\
\hline \multicolumn{8}{|l|}{ P-Out: } \\
\hline Free ............................ & $3.3(12.9)$ & $10.0(18.7)$ & $13.0(18.0)$ & $12.3(17.6)$ & $25.5(26.4)$ & $39.3(29.4)$ & $17.2(23.8)$ \\
\hline Wh- ........................... & $76.7(41.0)$ & $83.3(28.0)$ & $87.0(18.0)$ & $87.7(17.0)$ & $74.5(26.0)$ & $60.7(29.0)$ & $78.3(28.0)$ \\
\hline 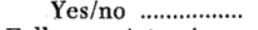 & $.0 \quad(.0)$ & $6.7(15.2)$ & $.0 \quad(.0)$ & $.0 \quad(.0)$ & $.0 \quad(.0)$ & $.0 \quad(.0)$ & $1.1(6.5)$ \\
\hline \multicolumn{8}{|l|}{ Follow-up interview: } \\
\hline \multicolumn{8}{|l|}{ Central: } \\
\hline Free .......................... & $27.4(19.5)$ & $39.5(16.4)$ & $39.2(16.6)$ & $54.9(22.5)$ & $66.1(15.8)$ & $82.5(15.2)$ & $51.6(25.5)$ \\
\hline Wh- ........................... & $38.4(19.8)$ & $49.4(16.1)$ & $49.7(21.0)$ & $37.7(21.1)$ & $28.5(13.9)$ & $13.9(15.8)$ & $36.3(21.6)$ \\
\hline 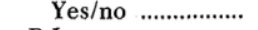 & $27.6(15.8)$ & $11.0(9.1)$ & $10.9(10.2)$ & $7.3(7.4)$ & $5.3(5.3)$ & $3.5(6.4)$ & $10.9(12.3)$ \\
\hline \multicolumn{8}{|c|}{ P-In: } \\
\hline Free & $8.9(18.7)$ & $16.6(22.6)$ & $19.1(22.2)$ & $35.1(26.4)$ & $30.7(16.4)$ & $54.1(25.5)$ & $27.4(26.2)$ \\
\hline Wh- ........................ & $57.8(45.8)$ & $83.4(22.6)$ & $77.5(22.9)$ & $58.2(29.4)$ & $69.3(16.4)$ & $45.9(25.5)$ & $65.4(30.6)$ \\
\hline Yes/no .................... & $6.7(25.8)$ & $.0 \quad(.0)$ & $3.3(12.9)$ & $.0 \quad(.0)$ & $.0 \quad(.0)$ & $.0 \quad(.0)$ & $1.7(11.7)$ \\
\hline \multicolumn{8}{|l|}{ P-Out: } \\
\hline Free & $4.9(12.9)$ & $21.1(36.4)$ & $13.0(20.7)$ & $13.3(16.0)$ & $37.7(20.4)$ & $47.3(20.2)$ & $22.9(26.4)$ \\
\hline 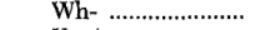 & $73.6(31.4)$ & $75.3(36.6)$ & $80.1(23.5)$ & $80.4(16.9)$ & $55.1(20.7)$ & $48.4(22.7)$ & $68.8(28.4)$ \\
\hline Yes/no .................... & $14.8(17.7)$ & $3.5(9.6)$ & $6.9(14.0)$ & $6.3(14.4)$ & $7.1(11.5)$ & $4.3(11.8)$ & $7.2(13.6)$ \\
\hline
\end{tabular}




\section{EMOTION}

Studies have shown that emotions can also affect the accuracy of people's memory. People's most vivid and lasting memories are emotional memories [11], so whether eyewitnesses' emotional state affects the accuracy of their testimony has been the subject of extensive attention by psychologists. Firstly, emotions do have an effect on memory, and that different emotional states have different effects on people's memories. A number of studies have found that memory capacity is stronger in negative emotions than in positive or neutral emotions. Humphreys et al. studied people's performance in recalling different emotional stimuli and demonstrated this idea. Participants viewed several pairs of emotionally neutral or non-emotionally neutral pictures, and during the viewing process, they were found to have stronger attention to positive pictures and weaker attention to negative pictures. But a week later the test showed that the participants' memory was enhanced for the negative pictures only. So they concluded that during the encoding phase of memory, people were able to have a deeper encoding of negative emotional information, and during the extraction phase of memory, the recognition standard for negative emotional information was low, so they could recognize more of it [12]. However, there is also evidence that people are less able to remember negative emotional information. For example, in Brainerd et al.'s study, they found that young people had more false memories for negative words only, because positive valuation can protect against memory distortion, in contrast, negative valence increased the familiarity of critical distractors with semantic content, and also reduced people's ability to use verbatim traces to suppress errors, thus stimulating participants' false memories, and resulting in inaccurate memory [13]. So while it is now impossible to determine exactly how positive and negative emotions affect memory, it is certain that they do cause false memories to be created, leading to a distortion of the original event.

Secondly, the emotions that precede an event can cause people to focus only on the information that is very important in it, thus impairing their memory of the whole event [11]. One of the most classic studies supporting this idea is the "weapon focus effect", which refers to the fact that in criminal cases, once a weapon is present, witnesses are more inclined to focus on that weapon and less inclined to observe and consider other aspects of the event, making it more difficult for the witness to recall other details [14]. Pickerell has studied the effects of the weapon focus effect. He asked participants to watch a video of a man with a gun and then describe his characteristics. The study found that when the gunwielding man's behaviour occurred in a reasonable context, their description of the man was accurate, but when the behaviour occurred in an unexpected context, their description was vague, yet there was no difference in the man's behaviour between the two videos. This suggests that the weapon focus effect occurs when a weapon appears in an inappropriate context that puts the witness on edge [15]. This is because the presence of a weapon is usually unexpected and sudden, that is, it does not correspond to the occasion, such as a shopping mall or a restaurant, in which case the weapon is bound to attract intense attention and. At the same time, it creates extreme fear in the witness, causing them to focus almost exclusively on emotional regulation and the effort to survive. This very narrow focus can then lead to a blurring of their memory of the events that caused this emotion. Conversely, the emotion after the event allows for increased witness attention, enabling them to encode additional details [11]. Gable and Harmon-Jones studied the effect on memory of the emotions that people generate before and after the event. Participants were asked to view photographs that evoked aversive emotions before the event, sad emotions after the event, and a neutral state, and their attention was tested separately. The results showed that attention was stronger when viewing photos that evoked sadness than when viewing photos that evoked disgust [16]. This is because the emotion after the event represents an evaluation of the event after it has already occurred, and people focus more on the consequences that arise, resulting in enhanced attention and more accurate memory [17]. It is therefore known that strong emotions generated by eyewitnesses prior to the event can make their memories much less reliable.

\section{CONCLUSION}

In conclusion, the research carried out by psychologists over the years in the field of the reliability of eyewitness testimony confirms that people's memories sometimes do not accurately reflect the real events, but are instead plastic, which has important practical implications for justice system. Firstly, it suggests that eyewitness testimony may be shaped by the integration of original information and external stimuli, such as the way in which questions are asked. Suggestive information in questions can mislead witnesses to take this information as if it had actually happened, thus producing a misinformation effect. The type of questioning can also have an effect on memory, openended questions allow witnesses to recall more freely than specific questions, the information will be comprehensive and the results will be more accurate. Secondly, emotions can also affect the reliability of testimony. Although there is no authoritative research at present that can confirm whether positive or negative emotions cause false memories to occur, it is certain that emotional values do affect people's susceptibility to false memories. Also, the weapon focus effect suggests that if a witness is in a stressful state, then they will focus most of their attention on what is important, resulting in a poorer memory for other things. So jurors should be as 
sceptical of eyewitness testimony as they are of any other kind of evidence. It would be unwise to accept the testimony of any witness without question.

Future research on the reliability of eyewitness testimony could be more in-depth. For example, psychologists can determine how various factors influence people's judgement, how positive and negative emotions actually affect people's memory accuracy, and why people's brains do not remember and recall things as well as they would like. And then combined them with justice, so that eyewitness testimony can have a positive and significant effect. In short, there is a bright future for the study of people's memories.

\section{AUTHORS' CONTRIBUTIONS}

This paper is independently accomplished by the author.

\section{ACKNOWLEDGMENT}

I would like to extend my sincere gratitude to Prof. Szucs, for his wonderfully designed course and a patient presentation that provided a lot of helpful information. I am also deeply indebted to Yilin Wang and all the other teachers for their consent encouragement and guidance, and direct and indirect help to me in the content and form of this essay.

\section{REFERENCES}

[1] Garrett, B. (2012). Convicting the innocent: where criminal prosecutions go wrong. Harvard University Press.

[2] Mudd, K., \& Govern, J. (2004). Conformity to Misinformation and Time Delay Negatively Affect Eyewitness Confidence and Accuracy. North american journal of psychology. 6,227-238.

[3] Votruba, A. M. (2013). Will the real reasonable person please stand up? Using psychology to better understand how juries interpret and apply the reasonable person standard. Arizona State Law Journal, 45(2), 703-732.

[4] Ruolong, Z., Feng, Y., \& Hui, Q. (2011). Psychological Summary of the Reliability of the Testimony from Eyewitness. Journal of Henan Judicial Police Vocational College, 9(4), 104-109. https://doi.org/1672-2663(2011) 04-0104-06

[5] Sutherland, R., \& Hayne, H. (2001). The effect of postevent information on adults' eyewitness reports. Applied Cognitive Psychology, 15(3), 249263. https://doi.org/10.1002/acp.700

[6] Loftus, E. F., \& Palmer, J. C. (1974). Reconstruction of automobile destruction: An example of the interaction between language and memory. Journal of Verbal Learning and Verbal Behavior, 13(5), 585-589. https://doi.org/10.1016/s0022$5371(74) 80011-3$

[7] Zaragoza, M. S., \& Lane, S. M. (1994). Source misattributions and the suggestibility of eyewitness memory. Journal of Experimental Psychology: Learning, Memory, and Cognition, 20(4), 934-945. https://doi.org/10.1037/0278-7393.20.4.934

[8] Meade, M. L., \& Roediger, H. L. (2002). Explorations in the social contagion of memory. Memory \& Cognition, 30(7), 995-1009. https://doi.org/10.3758/bf03194318

[9] Zaragoza, M. S., \& Lane, S. M. (1994). Source misattributions and the suggestibility of eyewitness memory. Journal of Experimental Psychology: Learning, Memory, and Cognition, 20(4), 934-945. https://doi.org/10.1037/0278-7393.20.4.934

[10] Peterson, C., \& Bell, M. (1996). Children's Memory for Traumatic Injury. Child Development, 67(6), 3045. https://doi.org/10.2307/1131766

[11] Kaplan, R. L., Van Damme, I., Levine, L. J., \& Loftus, E. F. (2015). Emotion and False Memory. Emotion Review, 8(1), 8-13. https://doi.org/10.1177/1754073915601228

[12] Humphreys, L., Underwood, G., \& Chapman, P. (2010). Enhanced memory for emotional pictures: A product of increased attention to affective stimuli? European Journal of Cognitive Psychology, 22(8), $1235-1247$ https://doi.org/10.1080/09541440903427487

[13] Brainerd, C. J., Stein, L. M., Silveira, R. A., Rohenkohl, G., \& Reyna, V. F. (2008). How Does Negative Emotion Cause False Memories? Psychological Science, 19(9), 919-925. https://doi.org/10.1111/j.1467-9280.2008.02177.x

[14] Loftus, E. F., Loftus, G. R., \& Messo, J. (1987). Some facts about "weapon focus.". Law and Human Behavior, 11(1), $55-62$. https://doi.org/10.1007/bf01044839

[15] Pickel, K. L. (1999). The influence of context on the "weapon focus" effect. Law and Human Behavior, 23(3), 299-311. https://doi.org/10.1023/a:1022356431375

[16] Gable, P., \& Harmon-Jones, E. (2010). The Blues Broaden, but the Nasty Narrows. Psychological Science, 21(2), 211-215. https://doi.org/10.1177/0956797609359622

[17] Kaplan, R. L., Van Damme, I., \& Levine, L. J. (2012). Motivation Matters: Differing Effects of Pre-Goal and Post-Goal Emotions on Attention and Memory. Frontiers in Psychology, 3. https://doi.org/10.3389/fpsyg.2012.00404 